\title{
RÄPINA PEREKONNANIMED JA LISANIMED
}

\author{
EVAR SAAR
}

Annotatsioon. Artiklis võrreldakse Räpina kihelkonna perekonnanimesid pastor J. F. Helleri omakäelises personaalraamatus ja 1826. aasta hingeloendites, vaadeldakse Helleri perekonnanimede tuletamise süsteemi ja antakse mõningate selle aluseks olnud lisanimede etümoloogia. Lisanimedest on analüüsimiseks valitud sellised, mis põhinevad vanal isikunimel, kuid ei seostu Võrumaal ja Eestis tänapäeval tuntud eesnimede ega sõnavaraga.

Võtmesõnad: perekonnanimed, lisanimed, nimetuletus, etümoloogia

\section{Sissejuhatus}

Räpina perekonnanimed, mis on suures osas saadud vanadest lisanimedest tuletamise ja liitmise teel, on Eestis tänapäevani ära tuntav perekonnanimede rühm. Eesti-saksa hübriidsete nimede või ing-lõpuliste nimede puhul tekib kogemuse pinnalt ikka küsimus, kas see nimi võiks pärineda Räpinast. Arvestades selles kihelkonnas pandud perekonnanimede (edaspidi: pn) erilist keelelist lahendust ja stiili täielikku ühtsust üle kihelkonna ning pärimuslikke teateid, on arvatud, et perekonnanimed pani isiklikult pastor Johann Friedrich Heller, kes töötas selles ametis 1814-1849. (Ritsing 1984; Must 1995: 166) Rahvasuust on pärimusekoguja Miralda Ehrlich 1931. aastal kirja pannud järgmist: „1822. a. sügisel aetud vallarahvas kokku ja küsitud igalt, missugust nime ta omale soovib. Suurem jagu said talu nime järele omale perekonnanime. Kes midagi soovida ei ole osanud, sellele pannud saksad oma äranägemise järele nimed“ (Ehrlich 2006 [1931]).

Heller (1786-1849) oli pärit Pommerimaalt Stolpe väikelinnast, õppinud Königsbergi ja Halle ülikoolis. Liivimaale tuli ta 1807. aastal, oli siin koduõpetaja ja jätkas õpinguid Tartu ülikoolis teoloogia alal. Enne 
Räpinasse tulemist oli ta 1812-1814 Vastseliina pastor. Pikal Räpina perioodil sai Heller tuntuks kirjamehena, kelle sulest ilmusid tartukeelsed kirikulaulude kogumikud. Keeleteaduslikult silmapaistvaks peeti tema artikleid Johann Heinrich Rosenplänteri Beiträges (1822, 1823), milles ta soovitas reformida eesti keele põhikäänete traditsioonilist kujutamist nominatiivi, genitiivi ja akusatiivina. (Kask, Laanekask 1987: 468). 1842. aastaks valmis tal suure eesti-saksa sõnaraamatu käsikiri, mis sisaldab eelkõige rikkalikku ja värvikat Räpina keeleainest, kuid milles ei puudu ka lõuna- ja põhjaeesti põhisõnavara laiemalt (samas).

Helleri nimepanekutöö kõige suurem omapära on see, et tal paistab olnud taotlus anda ainult selliseid perekonnanimesid, mida saab seostada tegelikust kasutusest võetud lisanimedega. Heller ei soovinud anda mitte ühtki perekonnanime, mis oleks lihtsalt sõna. Sama lisanimega, kuid mitte lähedalt suguluses olevate perede eristamise abivahendiks kujunes nimede tuletamine. Kui keegi saigi perekonnanime assotsiatsiooni alusel, näiteks Ruusa mõisa tisler Pedo Zederbaum 'seedripuu', võib selliste juhtumite taga oletada aktiivse talupoja enda soovi. Peedo vend sai perekonnanime Aripa talu järgi, kuhu ta oli koduväiks läinud Josep Arripand (EAA.1269.1.796: 142, 221, L 318, 534, lühiviitena edaspidi PR).

Tuletamise teel moodustatud perekonnanimed lasksid vanal lisanimede traditsioonil edasi kesta ja järgmise 50-150 aasta areng kujundas omapärase nimesüsteemi. Räpina kihelkonna keskosa elanikud olid veel 1990. aastatel harjunud, et igal inimesel (ka teist tüüpi perekonnanimega sisserändajal) pidi ametlikule perekonnanimele lisaks olema külakeelne nimi. Elanikke ei kutsutud talunimede kui kohanimede järgi, vaid talusid kutsuti neis elavate suguvõsade külakeelsete nimedega, mis sisuliselt olid ikka needsamad vanad lisanimed. Kuigi osa XIX saj alguse lisanimedest oli 1990. aastateks kadunud (ja neist saadud perekonnanimed samuti), toetasid ülejäänute kasutamist perekonnanime-lisanime kindlad paarid. Aja jooksul tekkis ka uusi nimepaare, näiteks selliseid, kus isalt saadud perekonnanimega seati vastavusse ema suguvõsa lisanimi või selles kohas varem elanud suguvõsa lisanimi. (Saar 1999) 


\section{Helleri personaalraamatust}

Peale 1826. aasta hingeloendite mõisate kaupa on säilinud Helleri enda käega kirjutatud Räpina koguduse personaalraamat ${ }^{1}$ aastatest $1816-1831$ (PR). Mõisati hõlmab see Räpinat, Ruusat (Toolamaa) ja kirikumõisat. Selles on paljude talupoegade ja perede juurde kirjutatud lisanimesid, mille järgi neid on kutsutud või kirja pandud. Märkuste lahtrisse tehtud sissekanded puudutavad peamiselt lähisugulust, eri paigus elavaid (mõisa nõudel mujale elama pandud) vendi ja lellepoegi on raamatu ulatuses vastastikku viidatud. Näiteks Jaama külas perekonnanime Pärkmann saanud on kirjas kui Perkaja Hanso Ello (Ello 'elu, talu, talupere', sks Gesinde vaste Helleril), aga nende Hofname 'mõisanimi' on Werrewa. Verevä nimega tähistati mõisa peetavates hingeloendites nende talu Jaama külas. Märkuses on viidatud Hansu vennale Peetrile Kõnnu külas ja Pärkäjätele (Pärkaja t) Meelva külas, kes olla küll samast soost, aga praegu juba kaugelt sugulased (PR: 13, L 86-87). Tõepoolest, Kõnnu külas elava Peetri pere sai sama pn Pärkmann, Meelva küla pered aga pn Pärkson (EAA.1865.2.71/5:37, 50, 52, 60, L 39p, 52p, 54p, 62p). Personaalraamatus on dokumenteeritud, mis kaalutlustel on valitud sama või erinev perekonnanimi.

Esialgu on personaalraamatus valitud perekonnanimi Hinrikson Jaanile (ja surnud venna Peetri lesele-lastele), kelle isa Kirchname 'kirikunimi' oli Pebo Hindrik ja Hofname 'mõisanimi' ${ }^{2}$ Kubja Hindrik. Kommentaar lisab, et Jaani isa on Märdi Pebo Jani Hindrik, aga sünniregistris seisab lihtsamalt Mardi Pebo Hindrik. Hiljem on samale perele hariliku pliiatsiga kõrvale kirjutatud Hindrikind, mis on kooskõlas hingeloendi nimega. Peale Peebo ja Kubja on sama suguvõsa kolmandaks lisanimeks olnud Häide: Heide Hindriko Paetre läsk Anne (PR: 15, L 90).

Palju kordub selles personaalraamatus lühend NebN - Nebenname 'kõrvalnimi'. Vahel on kõrvalnimeks näiteks ametinimetusel põhinev

${ }^{1}$ Personaalraamat oli koguduseliikmete nimekiri perekonniti (sks Personalbuch). Sellel ajajärgul kordus tiitlis enamasti sõna Seelenverzeichnis või samatähenduslikult Henge Ramat.

2 Pere lisanimi XIX saj alguse hingeloendites on alati seesama, mis Helleri määratluses mõisanimi, sest hingeloendeid koostasid mõisaametnikud. Läänepoolsel Võrumaal võib seda nimetada väljakujunenud talunimeks, aga Räpinas mitte. Kuigi kohaseos on siin püsivam, esines ka nendes nimedes 1795-1826 arvukalt muutusi, mis tulenesid perede vahetumisest taludes. Näiteks ühest külast teise viidud pered võtsid ka hingeloendite järgi enamasti oma vana lisanime kaasa. 
lisanimi, juhul kui põhinimi näib olevat sugulusliinis päritud. Helleri kirja pandud kõrvalnimi võib olla üllatavalt pikaealine. Näiteks Tolmo Jakobi poeg Paap sai pn Tolmov, aga personaalraamatus seisab ka, et mõisa- ja kõrvalnimi on Kirbo (PR: 208, L 510). 1997. aastal teadsid paljud Räpina valla lääneosa keelejuhid, et iga Tolmovit kutsutakse külakeeles nimega Kirp. Nimi, mis XIX saj alguses figureeris mõisakirjas Leevaku küla talunimena, oli säilinud suguvõsa mitteametliku lisanimena, kuigi nad enam ammu Leevakul ei ela.

Helleril on veel üks korduv väljend: Leutname 'rahvanimi', vahel ka die Leute 'rahvas', mille rõhutamisega soovitakse näidata, et see erineb mõisanimest: HofN Kubja, die Leute: Pabo (PR: 4, L 8). Selle isikunime järgi saadi pn Paabusk. Kui 1826. a hingeloendi põhjal ei paista seost kõigi pandud perekonnanimede ja kirjas olnud lisanimede vahel, siis vaatlusaluses personaalraamatus on perekonnanimele aluseks saanud lisanimi mitme võimaliku hulgas alati näha.

Olgu siinkohal toodud veel üks näide talupoja paljunimelisuse kohta. 1826. aasta hingeloendi järgi Kõnnu küla Andrese talus elanud, pn Häideson saanud Peep Peetri poeg on Helleril kirjas kui Heide Petre Peep, kuid perele on lisatud veel nn kirikunimi Solna, mõisanimi Andrese, vanaisa nimi Andres, kohanimi Radama, lisaks rea kohal nimi Tanni, mis võib olla lisatud vanaisa nime Andres täiendusena, ja elukoha määratlus: Konno. Tunga Jakob Ello (59) (PR: 90, L 220).

Personaalraamatus on kogudusse tulnud isikud, kes olid perekonnanime varem ja teises kohas saanud, sisse kantud nii perekonnanime kui ka traditsioonilise lisanimega, nt perekond Pöld (Põld) perekonnapeaga Kure Juhani Kersna Vastseliinast (PR: 119, L 274).

Kõigi perede nimede võrdlus Räpina mõisa Kõnnu küla ulatuses näitab, et Helleri omakäelises personaalraamatus ja 1826. aasta hingeloendis olevad perekonnanimed langevad üldjoontes kokku. Küll aga on näha, et personaalraamatusse on hingeloendiga kokku minevaid perekonnanimesid hiljem lisatud ja üle kirjutatud. Näiteks Kriguli Peetri Jaagu ja Jakobi puhul on perekonnanime lahtrisse esialgu kirjutatud Krigul ja hiljem sellest tehtud Kriguland (PR: 85, L 210). Hedoske Jakobi Adole kõrvalnimega Parma on esialgu määratud pn Parmann, kuid hiljem juurde kirjutatud hingeloendiga kokku minev pn Heddosing (PR: 87, L 214). Ülime Paabu Joosepile on alguses antud pn Üllim, kuid hiljem on täiendatud seda liitega Üllimson (PR: 89, L 218). Listago Peetri Jaanile, kellel on kõrvalnimi 
Sombra (mõisanimest, nagu ilmneb märkusest), on esialgu kirjutatud sidekriipsuga perekonnanimi Sombra-Listak. Hiljem on personaalraamatusse juurde kirjutatud see nimi, mis perekonnale tegelikult anti: Listakson (PR: 94, L 228).

Kõnnu külas esineb vaid kaks parandamata jäänud erinevust kahe allika perekonnanimede kujude vahel. Soe lisanimega pere nimele Soemann personaalraamatus vastab Soeson hingeloendis. Seevastu personaalraamatus üksnes lisanimest Uusna tehtud perekonnanimele vastab hingeloendis Uusning. Mõlemast nimest läksid tegelikult kasutusse hingeloendi variandid. Nende juhtumite kohta saab öelda, et hariliku pliiatsiga tehtud parandused pole olnud lõpuni järjekindlad.

Siiski ei saa väita, et Heller täiendas personaalraamatut 1826. aasta hingeloendist otse maha kirjutades. Hooletusviga hingeloendi nimekujus Kritzerning tuleb välja, kui võrrelda personaalraamatu nimekuju Kristzerning. See on Kristova Peetri Jaanile antud nimi, mis peale Kristova lühenduse sisaldab ka teist lisanime Zerna ja nimelõppu -ing (PR: 90, L 220). Hingeloendi koostaja tegi ümberkirjutusvigu ka täpitähtede puhul, muutes näiteks täppidega markeeritud oe-diftonge: Soëberg $>$ Söeberg. (EAA.1865.2.71/5:32, 57, L 34p, 59p)

Allikaid võrreldes jääb mulje, et vaadeldavas personaalraamatus tegi Heller perekonnanimede panemiseks eeltööd, pani paljud nimed ka ära, aga lõpptulemus muutus väga palju. Uutesse, 1826. aasta hingeloenditesse kirjutati perekonnanimed küllalt mahuka kaalutlemise ja ümbertegemise tulemusena. Tagantjärele personaalraamatusse tehtud täiendused võis Heller võtta nimemääramise töö mustanditest, mis temale jäid. Küsimus, kas nimed mõtles välja Heller ainuisikuliselt või oli tal ka abilisi, kellel oli võimalus omatahtsi perekonnanimesid genereerida, jääb jätkuvalt lahtiseks. Küll aga on personaalraamatu põhjal hästi näha, et perekonnanimede tuletamise mudel sündis Helleri peas, ent võttis ilmet ja täiustus töö käigus.

\section{Räpina nimetuletuse põhijooni}

Kursiivis nimede kirjapildid on vanas kirjaviisis, antud 1826. aasta hingeloendite, mitte nende registrite järgi, kus leidub ohtralt ümberkirjutusvigu. Püstkirjas lisanimed põhinevad autori 1990. aastate välitööde andmetel ja on esitatud häälduslähedases kirjaviisis. 


\subsection{Tuletamata perekonnanimed}

Tuletamata perekonnanimed moodustavad Räpina perekonnanimede koguhulgast (ligemale 900) suhteliselt väikese osa. Seda tüüpi perekonnanimesid pandi igal pool Eestis. Räpinas loodi niimoodi ainult umbes 7\% kõigist perekonnanimedest. Teistes Võrumaa kihelkondades (nt Põlva ja Urvaste), kus lisa- ja talunimesid maksimaalselt ära kasutati ning tuletisi süstemaatiliselt ei tehtud, oli seda tüüpi perekonnanimede osakaal hinnanguliselt kindlasti suurem kui 7\%.

1. Lisanimi genitiivi kujul: Häide, Kirrota, Luido, Mälleto, Serne (<Zirna), Uusna, Walge, Wija

2. Lisanimi konsonantlõpuga (tegelik või kunstlik nominatiiv): Hawakar, Hering, Hiwask, Härmann, Hüss, Hütt, Iwand, Iwask, Jöcks, Karnask, Karrask, Karrigall (<Karrijalla 'karjala'), Krabb, Kress, Krigul, Kuningas, Kunn, Kuns, Köps, Kübbar, Küüts, Lappard, Lätt, Markus, Munsk, Narrusk, Parm, Poosk, Prittik, Puks, Rikkand, Ritsik, Rummask, Rämman, Sabbal, Sell, Sults, Sutt, Sälits, Zimm, Teppask, Teresk, Terrep, Tibb, Tils, Tenno, Toots, Truuts, Täll, Urm, Ust, Warrusk, Wämps, Üllim

3. Lisanime lühendamine kaugemale kui konsonantlõpuni: Hämmal (< Hämmälase), Sohha (< Soharra 'Soohara'), Warrus $(<$ Warruski)

\subsection{Tuletatud perekonnanimed}

Vokaal- või konsonantlõpulisele lisanimele on lisatud eristav lühike nimelõpp. Mõnikord on tuletises lisanime viimast vokaali varieeritud.

1. -r: Adur (<Ado), Hennor, Holster (<Holsti), Jusar, Käsnar, Kiislar, Kissar, Kiwitar, Klimar, Konsar, Kontkar jne. Arvukas rühm, mille tuletuseeskuju võis olla saksa keele -er. Saksa perekonnanimedes märgivad er-tuletised ametinimetusi, pärinemist mingist kohast, kuulumist kellegi perekonda jm (DLF: 202). Tänu nime aluseks olnud lisanimede sagedasele tüvevokaalile - $a$ sarnanevad tekkinud nimed rootsi ar-lõpuliste tuletistega.

2. -k: Hindok, Häidek, Kennik, Kerok, Klimak, Küttik, Limak, Parmak, Pindek (< Pindi), Pundek, Punnek (< Punni), Silack, Sussik, Söbrak, Zirnak, Tensok, Warack. Sõnatuletuses tundis Heller 
lõunaeesti arhailist (naissoo)liidet - $i k$, esitades oma sõnaraamatus kuju Wennik' venelanna' (Kask, Laanekask 1987: 472). Teatavat eeskuju on ehk pakkunud ka nominatiivis $k$-ga lõppevad lisanimed, nagu Ajalik, Pritik ja Riivik.

3. -sk: Adusk, Dobrask, Häidesk, Hallisk, Hargisk, Härmask, Karindosk, Kirrotosk, Klimask, Limask, Menisk, Oinask, Pabusk, Parmask, Parrisk, Pedesk, Pedosk, Punnisk, Raudnask (< Raudna), Rämmask, Sabbalisk, Simulask, Solnask, Zernask, Zirnask, Todesk, Tolmusk, Warask, Wijask, Wikkisk jpt. Sellele arvukale rühmale võivad olla eeskuju pakkunud lõpuosas $s k$-d sisaldavad lisanimed, nagu Ivaski, Karaski, Karnaski, Munski, Naruski, Rumaski, Tepaski, Tereski, Varuski, Wallaski. Keelelise konnotatsiooni tõttu võib sk-nimesid tajuda nimisõnadena, nt nõnask 'ninamees', pudisk 'pudikeelega inimene' (VEV), kuigi Räpina kihelkonna keelest võib leida ka adjektiivse kasutuse näite: libask pini 'lipitseja koer'. Mõned perekonnanimed selles rühmas, nagu Jonask, Udrask, Warresk, sisaldavad $s$-i juba lisanime nominatiivikujus.

4. -(o)n: Andron, Himmaksen, Juggon, Kangron, Kirroton $(<$ Kirrota), Michallon, Mälton (< Mäleto), Prokowon. Nimelõpu valiku motiiv näib olevat olnud venepärasus. Neli seda tüüpi nime antigi vene perekondadele. Iseenesest oli aga Helleri lahendus vene keele ja kolme läbipaistva isanime (Andrei, Mihhail, Prokofi) seisukohalt ebatüüpiline. Peale hariliku patronüümilõpu -in esineb muule vokaalile järgnevat $n$-lõppu vähesel määral Ukraina nimedes (Unbegaun 1995: 26, 220).

5. -(e)p: Kangrep (< Kangro), Konsap, Menep (< Meeni), Märdep (< Märdi), Punnep (< Punni), Ziugap, Wijap.

6. -(a)s: Kirrotas, Warruskas $(<$ Warruski).

7. -(a)ts: Häidets, Hargats (< Hargi), Hörats (< Höörä), Klimats, Luhhats, Menits, Mähhats, Naglats, Oinats ja Oinits (<Oina), Parrits, Punnits, Silats, Tungats, Warats, Wikkits, Woikats (< Võika).

8. -ks: Häideks (< Häide).

9. -nd: Arripand (< Arripa), Dobrand, Hindrikind ( $<$ Hindriku Hindrigi), Hörand, Hüssind, Jagund, Jusand, Kahhand, Karand, Karnaskind, Karund, Kikkand, Kiriland, Kirrotand, Kisland (< Kiisla), Kissand, Kiwand, Klimand, Koddowand, Konsand, Kontkand, Krigulind ja Kriguland $(<$ Kriguli), Kristowind $(<$ Kris- 
tova), Kriwand, Listakind ( $<$ Listaku), Menind, Munskind, Nagland, Narruskind, Obrand (< Obre), Parmand, Parrind, Puksand, Rummaskind, Röbind, Rusand, Sabbaland (< Sabbali), Siland, Simuland, Sokkand, Solnand, Söbrand, Zernand, Ziugand, Teppaskind, Tilgand, Tolmand (< Tolmo), Torriland, Warand, Wijand, Wikkind, Woikand. Selle arvuka rühma puhul tuleb tähele panna, et nime aluseks oleva lisanime tüvest ja $n d$-lõpust saadud -kind, -land ja -mand on mõnikord kujunenud edasise nimetuletuse vahendiks. Liitumisel tekkinud nimelõpud on alla joonitud. Keeleliselt pidi $n d$-tuletus Hellerile tuttav olema põhisõnavarast - imänd 'emand' ja esänd 'isand' - ning perekonnaterminist kasvand 'kasulaps'.

10. -kind: Häidkind ja Häideskind (< Häide).

11. -land: Lepland (< Lepikese), Mäeland, Oijoland (<Oijo), Puksland ( $<$ Puksa), Ritsland ( $<$ Ritśka), Wirroland ( $<$ Wirrolasse).

12. -mand: Höörmand ( $<$ Höörä) - tegu võib olla $d$-tuletusega perekonnanimest Höörmann, mitte Kliimandi, Parmandi jt eeskujul saadud moodustisega.

13. -rd: Kirrotard, Kiward, Kosard, Kristoward, Kübbard, Mähhärd, Sapperd, Sohard, Ziugard, Wijard, Woikard. Peaaegu kõik need nimed (v.a ebaselge motiiviga Sapperd) on moodustatud $a$-tüvele liitmise teel, kuigi - $r$ on olemas juba nimede Kübard ja Sohard (< Soohara) tüvedes. Vanadest lisanimedest sisaldas $\underline{r d}$-d Lapardi. Võib-olla on need juhtumid $r d$-tuletistele eeskujuks olnud. Sõnavaralistest eeskujudest on võimalikud oherd 'oherdi' ja pejoratiivne lupard 'kalts, närts, lontrus'. rd-lõpuline on ka mitmest lisanimest koosnev Juusward (Juusa + Vaara $+-d$ ).

14. -rb: Kirrotarb - ebaharilikult suure eristamisvajaduse tõttu Kirota lisanime kandjate hulgas on tehtud vaid üks $r b$-lõpuline perekonnanimi.

15. -rz: Urgarz - ainsa selle lõpuga nime põhjus oli ilmselt täiendav nimetamisvajadus.

16. -ow: palju on otseselt vene perekondadele pandud nimesid, mis korduvad slaavikeelsete nimedena mitmel maal. Allesitatud valik sisaldab ainult Räpina või ka Räpina tänapäevani säilinud priinimesid, millel Eesti rahvastikuregistris -ova naisvasted puuduvad või on neid oluliselt vähem: Dobrow, Hannow, Heidow, Hindow, Hämmalow, Karow, Kerow, Leppikow, Mattow, Menow, 
Narruskow, Oijow, Puksow, Ziugow, Zängow, Tichanow, Tennow, Tolmow, Wanckow, Warow, Warunow, Willakow, Woikow.

17. -(i)ng: umbes neljandik ing-lõpulistest perekonnanimedest sisaldab lisanime tüvevokaalina $i$-d: Harging, Holsting, Hüssing, Jürring, Kesling, Korwing, Krabbing, Kütting, Lauring, Lätting, Mening, Ootsing, Pading, Parring, Pinding, Prehhing, Punning, Röbing, Rootsing, Sultsing, Tanning, Terreping, Tibbing, Wahhing, Wikking. Puhas, $u$-le liituv $n g$-lõpp on siiski vaid ühes nimes: Wössung ( $<$ Võso). Lisanime tüvevokaaliga mitte arvestav -ing oli Helleri jaoks üks keskseid nimetuletuse vahendeid, arvukuselt -sk ja $o w$-iga võrdväärne. Selle alarühma nimedest on tänapäeva Eestis säilinud näiteks Hansing, Härsing, Janikesing, Kalling, Kiriling, Konsing, Kristowing, Liming, Musting, Obring, Parming, Puksing, Raudsepping, Runing, Rusing, Saksing, Zupsing, Talliwätsing, Tensing, Tiggasing, Toding, Tolsting, Wätsing. Kuigi Heller oli lõpu -ing kasutamisel ilmselgelt mõjutatud teistest keeltest, tuleb siinkohal siiski arvestada $n g$-tuletusliite võimaliku toetava taustaga. $n g$-liide on küll tänapäeva eesti kirjakeeles väheproduktiivne, kuid võru keeles on selle kasutatavus suurem: hainang 'heinaaeg', muting 'viga, rike', (päävä)nõsõng '(päikese) tõus', nüssäng 'lüpsiaeg', palang 'põleng', sulõng 'veesulg, pais' jt, vrd ka saksa laensõna mugandamist: Teppich > tepping 'vaip' (VEV). Otseselt ing-nimelõpu võõrkeelsetest eeskujudest võis olla määrav germaani keelte, eriti alamsaksa ja selle lähimate sugulaskeelte -ing ajaloolises tähenduses 'kellegi järeltulija', nagu perekonnanimes Nolting 'Nolte poeg, Nolte järeltulija' (DLF: 313). Hellerile tuntud paralleeliks võis olla ka läti isikunimedes ülisage deminutiivsufiks -iņš, mida läti vanas kirjaviisis kirjutati kujul -ing, nt Behrsing (Bērsiņš).

18. -sing: lisanime ja nimelõpu kombinatsioonis (nt Warres|ing) tekkinud -sing osutus sobivaks ka $s$-i mitte sisaldava lisanimega liitmiseks: Jagosing, Karosing, Parmsing ( $<$ Jaago, Kaaro, Parma).

19. -ding: arvukatele Parma lisanimega suguvõsadele tuletati nimeseeria, kuhu kuulusid peale nime Parming ka Parmsing ja Parmading. 


\subsection{Sõnalist formanti liitvad nimed}

Vokaallõpulisele või konsonantlõpuliseks lühendatud lisanimele liideti täistähenduslik sõna, mis perekonnanime osana ei ole siiski liitsõnaosis, vaid nimeformant ${ }^{3}$. Kõik viis kasutatud sõna ja üks tekkinud kombinatsioon olid saksakeelsed, seega olid tekkinud perekonnanimed hübriidnimed. Suurematesse näiteloenditesse (1-3) on valitud nimed, mis on Eestis tänapäevani säilinud.

1. -son: Adamson, Ewertson, Hanson, Heringson, Härmson, Härsson, Hüsson, Jaansson, Jagoson, Jonasson, Karpson, Kaurson, Kirrotson, Klimson, Konson (< Konsa), Krigulson, Kustawson, Kütsson (< Küüdse), Lipson, Narrusson, Paapson, Parmasson, Parmson, Parson (< Pari), Pedoson, Pedson, Pentson, Pintson, Pukson, Punnisson, Punson, Raudson, Röpson (<Rööbi), Sabbalson, Sakson, Sultson, Soeson, Solnson, Zupson, Tenson, Terrepson, Tilkson, Türkson, Urtson, Waltson, Warrusson, Wikson, Willemson, Wätson (< Vätsä). Tervikuna on formandiga -son moodustatud rühm Räpina perekonnanimede hulgas kõige suurem.

2. -mann: Arripmann, Harkmann, Jagomann, Kaarmann (< Kaaro), Keertmann, Kellmann, Kesselmann ( $<$ Kesli), Klimann, Kokmann, Kärtmann, Kütmann, Lilmann, Lindmann, Liiskmann, Märtmann, Naggelmann, Otsmann, Paalmann, Puksmann, Parmmann, Pedmann, Pintmann, Punmann, Röpmann, Saksmann, Sepmann, Simulmann, Sokmann, Suurmann, Ziugmann, Zupsmann, Zängmann, Tensmann, Tolmann ( $<$ Tolmo), Tootsmann, Treumann, Waarmann, Wickmann $\sim$ Wikmann.

3. -berg: Adoberg, Häidberg, Hansberg, Jagoberg, Karlberg, Klimberg, Konsberg, Kunberg, Lamberg, Lemberg, Narrusberg, Oinberg, Röberg (> Rüüberg), Siilberg, Silaberg, Tannberg, Tensberg, Wössoberg.

4. -bek -beck 'oja': Häidbek, Kirrutbek, Kliimbeck, Menbek, Narbek, Narrusbeck, Oinbek, Ritsbek, Siilbek, Soebek, Tensbek.

5. -baum 'puu': Raudbaum ( $<$ Raudsepä), Siilbaum ( $<$ Siila).

${ }^{3}$ Perekonnanimedes rõhutab liidetud sõna lihtsalt kogu nime kuulumist sellesse nimeliiki, mingit uut tähendust (nt „,kelle poeg?“, „missugune mägi?“) selliselt kombinatsioonilt ei oodata. 
6. -dorw, vrd Dorf 'küla': Häidorw, Kiudorw. Tegelikult liideti lisanimele ühel juhul -orw ja teisel vaid $-r w$.

Kokkuvõtlikult on lisanimede osadest ja liidetud osadest moodustunud tajutavalt saksakeelsed sõnad -kind 'laps', -land 'maa', -sing (verbi laulma tüvi), -ding 'asi' ja -dorw, vrd Dorf 'küla'. See, et tuletusmängus midagi selletaolist tekkis, näib olevat olnud nimede väljamõtlejale meelepärane.

\subsection{Muud võimalused perekonnanimede loomiseks}

Eri perekonnanimede loomisel kasutas Heller aluseks võetud lisanimede häälduslikke ja kirjapildivariante (allonoome): Hiwask ja Iwask, Lima- ja Klima-, Mälleto- ja Mält-, Pent- ja Pint-, Zern- ja Zirn- jt. Sellist varieerimist esineb Helleril siiski suhteliselt vähe. Tuleb rõhutada, et osa sama algnime lähedasi mugandusi oli allonoomidest erinevateks kirjalikeks lisanimedeks kujunenud juba enne perekonnanimede panemist, nt Iwandi ja Iwaski, Pede ja Pedo, Terrepi ja Terreski.

Helleri nimetuletuse üks läbiv omapära on lisanime lühendamine. Mõnikord on seda tehtud kõigi tuletiste puhul, nt lisanimest Urgawa on saadud ainult tüve Urga- ja nimelõpu ühendeid: Urgand, Urgar, Urgard, Urgarz ja Urgask. Kohanimest Soharra (Soohara) on saadud ainult Sohavõi Sohha- ja nimelõpu ühendeid, välja arvatud Sohard, mis oletatavasti andiski tõuke lühenenud tüve tajumiseks: Sohar $\mid d>$ Soha|rd. Enamasti on täieliku ja lühendatud tüvega variantide loomine lihtsalt aidanud erinevate nimede hulka kasvatada. Pikkade lisanimede puhul on lühendamine siiski valdav. Lühendatud lisanimele on lisatud nimelõpp: Hawaka|ts (< Hawakarri), Hindri|ts (< Hindriku), Hämmal low (< Hämmälase), Janik|son (< Jaanikese), Krigu|ts (< Kriguli), Lep|mann, Leppi|sk, Leppi|ts, Lep $\mid$ son (< Lepikese), Lista $\mid r$, List $\mid$ mann (< Listaku), Mäl|berg, Mäl $\mid$ mann (< Mäleto), Pärk|ow, Pärk|mann, Pärk|son (< Pärkäjä), Rauda|sk, Raud|mann jt Raud-algulised perekonnanimed (< Raudsepä), Rits $\mid$ ing, Rit|son ( $<$ Rits'ka), Serba|sk ( $<$ Serbagu), Sohha $\mid$ sk ( $<$ Soohara), Söuka $\mid$ nd ( $<$ Sõukõsõ), Warre $\mid$ nd $(<$ Warresse $)$ jpt. 


\subsection{Kompleksse struktuuriga nimed}

1. Mitut lõppu ja formanti sisaldavad nimed. Hingeloendite nimede järjekorrast on vahel näha, et perekonnanimesid on tehtud juba valmis saanud nimesid edasi tuletades: Häid|berg|son, Häide|sk|ow, Parma $|k|$ son, Puksa $\mid$ nd $\mid$ ow, Sila|ts|ing. Silmatorkavaim alarühm nende hulgas on -man(n)son: Häid|man|son, Hör|man|son, Lep|mann|son, Par|man|son, Ped|mann|son, Raud|mann|son, Sil|man|son, Wik|mann|son, Woik|mann|son.

2. Mitut lisanime sisaldavad nimed. Nende loomisel võisid eeskujuks olla mitut pärisnime sisaldavad rahvapärased lisanimed, nagu Talli|wätsa, ja liitsõnalised lisanimed, nagu Karp|seppa. Ka mõned ühest isikunimest saadud lisanimed olid pikemad, leidus koguni neljasilbilisi, nt Hawakarri.

Semantiliselt oli seda tüüpi nimede aluseks peamiselt sama isiku mitu lisanime. Vahel tuleb see välja Helleri personaalraamatust, nt Raudseppa od. Kütti Mikko Josep sai perekonnanime Raudkütt (PR: 22, L 104). Nimi Silanarrusk anti Naruski Mihkli järeltulijatele, kelle perenimi (Gesindename) oli Siila. Naruski juurde märgitud lisanimi Tilgo jäi perekonnanimes kasutamata (PR: 156, L 342). Mõnel juhul on aga tegu lisanimede ajaloolise järjendiga. Nimelt elas aastatel 1722-1803 Siila Ivaski Juhan (EAA.1865.2.70/12:5, L 5), kelle isa võis olla 1738. aastal mainitud Kassako Sila Iwasck Pääsna külas (EAA.567.3.191:52, L 71p). Juhani lastele pandi perekonnanimi Sil|iwask. XIX saj alguses elas see suguvõsa juba Süvahavval ja neid pandi mõisakirja lihtsalt Iwaski lisanimega. Samasugune nimetamisviis oli sealkandis säilinud 1990. aastatel: külakeeles Ivaski, ametlikult Siil-ivask.

Nimelõppe ja formante mitte sisaldavate liitnimede loetelu on järgmine: Hark|narrusk (< Hargi + Naruski), Häid|hüss (< Häide + Hüssi), Häid|rits (< Häide + Ritśka), Höra|wikk (< Höörä + Viki), Kaar|jask ( $<$ Kaaro + Jaaska), Kal|häid ( $<$ Kalle + Häide), Karo|punn ( $<$ Kaaro + Punni), Kiis $\mid$ häid (< Kissa või Kiisla? + Häide), Kissa|kress ( $<$ Kissa + Krõssi), Kons $\mid$ wikk ( $<$ Konsa + Viki), Krigul|wik $(<$ Kriguli + Viki), Kriis $\mid$ kütt ( $<$ Kriisa + Küti), Libbo $\mid$ kunn ( $<$ Libbo? + Kunni), Lokko $\mid$ wikk $(<$ Lokuta + Viki), Möldre|holst $(<$ Möldre + Holsti), Narrus $\mid$ trang ( $<$ Naruski + Trangi), Puksa $\mid$ wikk ( $<$ Puksa + Viki), Raud $\mid$ kütt ( $<$ Raudsepä + Küti), Sila|narrusk ( $<$ Siila + Naruski), Sil|iwand (Siila + Ivandi), Sil|iwask (< Siila + Ivaski), Tammo |kunn (< Tammistu + Kunni), Wer $\mid$ wikk 
(Verevä + Viki). Nt Tooste küla Viki talus pandi korraga kolm seda tüüpi perekonnanime (PR: 110, L 258). Tavapäraseks on kujunenud komponendiks oleva lisanime lühendamine.

3. Mitut lisanime ja nimelõppu sisaldavad nimed. Nende hulka kuuluvad Häid|jonas|ing ( $<$ Häide + Jonase), Höra|woik $\mid$ ow $(<$ Höörä + Võika), Juus $\mid$ war $\mid$ d (< Juusa + Vaara), Kaar $\mid$ häid $\mid$ ing $(<$ Kaaro + Häide), Kar $\mid$ otsi $\mid$ ng ( $<$ Kaaro + Oodsi), Kir $\mid$ häid $\mid$ ing ( $<$ Kirota + Häide), Kont $\mid$ häide $\mid k$ (< Kontka + Häide), Krist $\mid$ zern $\mid$ ing $(<$ Kristova + Tserna), Leppi $\mid$ karo $\mid$ w (< Lepikese + Kaaro), Meni $\mid$ warres $\mid k$ ( $<$ Meeni + Varõssõ), Nar|obr|ing (Naruski + Obre), Puks|lom |ing (< Puksa + Loomussõ), Raud $\mid$ häid $\mid$ ing (< Raudsepä + Häide), Raud|leppi|ts (< Raudsepä + Lepikese), Raud $\mid$ mak $\mid$ ind (< Raudsepä + Makõ), Sör|punni|sk (< Sõra + Punni), Tolm $\mid$ wäts $\mid$ ing $(<$ Tolmo + Wätsa). Osa seda tüüpi nimesid võib olla loodud nii, et juba valmis nimele, nt Woikow, Ootsing, Zerning, Obring, Leppits ja Wätsing, on ette lisatud teine lisanimi (lisanimelühend). Väärib märkimist, et kohalikus keelekasutuses eristuvad liitunud lisanimede piirid tänapäevani. Nii nagu [siil-ivask], on ka [kaar-ootsing] kohalik hääldus Mehikoormas, kuigi nime kirjapildist Karotsing võiks tajuda tsing- või ing-lõppu.

\section{Räpina lisanimede päritolust}

Eesti perekonnanimeraamatu (EPNR) koostamise käigus analüüsiti neid lisanimesid, millest on saadud vähemalt üks vähemalt 30 kandjaga perekonnanimi. Mõned raamatu käsikirjas leiduvad perekonnanimed on Räpina kihelkonna omad vaid riivamisi - need on nimed, mida on pandud ka mitmes muus kohas. Praegu on käsitletud kokku 82 tüüpiliselt Räpina, sh Räpina lisanime (mõne käsitluse autor on Udo Uibo, Marja Kallasmaa, Mariko Faster või Enn Ernits). Esitan alljärgnevalt valiku tüüpiliselt räpinapäraste lisanimede etümoloogilistest seletustest, milleni jõuti selle töö käigus.

Lisanime hääldus on esitatud märksõnana sellel kujul, nagu see esineb Räpina kohanimedes ja rahvapärase suulise lisanimena. Kadunud lisanimi on antud kursiivis vanal kirjalikul põhikujul. XVIII saj lõpu ja XIX saj alguse Räpina mõisate hingeloenditele pole lühiduse huvides viidatud, sest see materjal on olulisem perekonnanimede kujunemisloos ja seda saab Eesti perekonnanimeraamatu kaudu hiljem kasutada. 
Küll aga olen lisanud teksti sisse lisanimede algse kujunemise näidete allikaviited.

Haavakari. Lisanimi säilis perekonnanimes Havakar, mis suri Eestis välja alles hiljuti. XIX saj alguse hääldus on varieerunud: [haavakari] [aavakari] [havakari]. Allikatest ilmneb, et see nimi kuulub inimese isanimede ritta: 1738 Aravul Lassare Hawa Karro Mick dito Hans ja Mehikoormas Socka Hawa Kari Paap, 1731 vastavalt Hawekary Peter Mick ja Soka Hawakarj Paap (EAA.567.3.190:111, 113, L 110p, 112p; EAA.567.3.191:64, L 83p). Võrreldavatest vene õigeusu eesnimedest on lähim Avvakir (Авваки́p), mis lihtsustunult esineb enamasti ühekordse v-ga: Аваки́p (Petrovskij 2005: Аввакир). Küsimusi tekitab vaid, kas laenulises lisanimes võisid vahetusse minna järelosise vokaalid *-kira $>$-kari. Teise hüpoteesi järgi koosnes Haavakari lisanimi kahest nimemugandusest: *Kaari $\sim$ *Kaaro - vn Gavril (Гавриил = Gabriel) ja *Haava *Hava omakorda kunagise * Kaari isanimena. 1582-1592 Toostes revisjoni kantud Jak Hawapoik Chawapoik (PA II: 336, 433) kandis sama isanime. Seda võib võrrelda eesti sõnaga haab : haava, kuid tõenäolisemalt on seegi lääneveneliku eesnime hüüdvorm ${ }^{4} \mathrm{Hava}$ (Xába), mis muutuse ( $\phi>$ $x$ ) kaudu võiks olla saadud ristinimest Fabius (Фавий) (Superanskaja 2010: 42, 342). EPNRis on Räpina ainunimi ${ }^{5}$ Havakats $\sim$ Haavakats.

Heeringe. Heering oli Põhja-Räpinas veel XVIII saj eesnimi. Perekonnanimede Hering ja Heringson saanute vanaisa Agalicko Hering (u 1693-1783) ei kandnud just väga haruldast eesnime, veel 1795. aastal leidus sama nime ka keskeas meestel. Kõige varajasem maining on Herrig ein Fischer 'Herrig, kalamees' 1627 Kasaritsas (Rev 1627: 89). Samast eesnimest kujunenud perekonnanimede hulka võib kindlasti liita ka Urvaste mõisas pandud nime Herik (ka Heerik), 1816 talupere Heeringe Maddis (EAA.1865.2.132/13:10, L 10p). Eesnimes on arvatavasti säilinud Lõuna-Eestisse XIII saj jõudnud keskaegne saksa nimi. Selle populaarsuse püsimisele võis kaasa aidata XVII saj Rootsi kaudu tuttavaks saanud ja

${ }^{4}$ Märgin terminiga hü̈̈dvorm nimekujusid, mis on levinud peamiselt suulises kasutuses ning mis on ametliku isikunime alusel tekkinud sekundaarsed hüüdnimed, aga mida hüüdnimedeks nimetades võib ehk jääda mulje, et need tekivad igale hüütavale individuaalselt. Soovin sellega rõhutada, et hüüdvormid on keeles valmis kujul olemas. Vene isikunimesüsteemis on see eriti selgelt näha. Hüüdvorm võib olla hellitav (= hellitusnimi), aga ei pruugi.

5 Ainunimi on ainult ühes kihelkonnas pandud perekonnanimi. 
vanema nimega samastatud Erik. Iseenesest samuti germaani nimi Erik (sks Erich) ei sisaldanud ka arhailisel alggermaani kujul $h$-d: *ēra + rīhhi (DLF: 203). See-eest tänapäevanimele Harald vastav alggermaani *harja + walda andis keskaegsel Saksamaal Hering- ja Häring-tüüpi nimesid, vrd nt kohanimed Herrig Põhja-Reinimaal, Herringen Vestfaalis (DLF: 292-293) ja Heringhausen Põhja-Hessenis. Põhja-Saksamaa hansalinnade regioonis esines see nimi pigem kujul Haring (DLF: 277), kuid just Vestfaalist lähtus teatavasti oluline osa XIII saj Liivimaale suundunud kolonistidest. EPNRi pääseb Heering Hering mitmel pool pandud ja erinevat algupära perekonnanimena, kuid nt Heeringson on Räpina ainunimi.

Häide. Räpinas põlist Häide lisanime on kirjutatud peamiselt Heide. 1638 on seda lisanime leidunud Kõnnu, Raadama ja Jaama külas, seejuures on Heide kõrval kasutatud ka pikemat kuju Heidlich. 1627 on samades külades kasutusel lisanimi Heidelick (Rev 1627: 69, 70; Rev 1638: 264, 266, 268), vrd Hargla kihelkonna talunimi Heitliku. Räpina vanimad nimekujud on siiski Heido Pawell Raadamal ja Heide Lauritz Räpina (Jaama) külas (Rev 1601: 17, 19). Häide lisanime päritolu kohta on kaks tõenäolisemat oletust. Esiteks, XVII saj alguse nimekuju vihjab tugevalt kaheosalisele germaani nimele Heidenreich, millel põhinevad saksa perekonnanimed Heidel, Heiderich jt (DLF: 284). Heiderich või selle nime lühemad vormid võisid tulla kasutusele keskaegses Eestis. Teiseks, kui XVII saj alguse kirjapanekud sisaldavad eestipärast lik-sufiksit, siis võiks kehtida Julius Mägiste oletus, et Eido (*Heido) on muinasaegne eesti isikunimi, vrd XVI saj Jan Ejtopoik ja XIV saj Aythe (Stoebke 1964: 15, 18). Eesti kohanimeraamatus on seda hüpoteesi toetanud Marja Kallasmaa Häidaste külanime ja Eidapere mõisanime korral. EPNRis on Häidberg kui Räpina ainunimi.

Härso. Põline lisanimi ilmus XVII saj kahes kohas: Veriora külas 1625 Horsa Pap, 1627 Herscha Pap, 1638 Hersewatz Pap, Meerapalus 1638 Herse Hansz. 1638 esines seda lisanime ka Haaslavas. (EAA.567.3.190:10, L 9p; Rev 1627: 72; Rev 1638: 226, 258, 278) Nähtavalt sama lisanime sisaldab Torma Võtikvere talunimi Ärsukese. Valdek Palli võrdlus Wiedemannil esineva vana mehenimega Eers : Eersu, mida seatakse vastavusse nimega Erich (PTK I: 288), võib olla sobiv, kui oletada, et Räpina Härsolisanime $h$ - on sekundaarne. Võrdluseks: teine Räpina vana eesnimi Heering seostub samuti nimega Eerik. Kõrvutuses vene õigeusu nimevaraga 
äratab siiski tähelepanu kalendrinime Jeleferi (Eлеферий) hüüdvorm Фе́рша Фе́ршо (Superanskaja 2010: 331), millest nii läänevenelikus kui ka lõunaeestilises muganduses võiks olla tekkinud $h$-ga algav variant, vrd vene ja ukraina perekonnanimi Heršov (Хершов). EPNRis on artikkel perekonnanimest Härsing, mis on Räpina ainunimi.

Jõksi. Räpina Jõksi lisanimi pärineb Pahtpää ja Kahkva külast. 1795 kirjutati seda Pahtpääl Jecksi ja Kahkvas Jexi, 1731 Pahtpääl Jekse, 1688 Pahtpääl Jäxe, Kahkvas Jaxe Jagßa, 1670 Kahkvas Jäxe. (EAA.567.3.190: 60, L 58p, SRA 1688: 202, 212, 257, 264, 1 199p, 209p, 254p, 261p; Roslavlev 1975: 28). Võrumaal ka Kanepis levinud Jõksi lisanimi põhineb tõenäoliselt vanal eesnimemugandusel, mille alus on Jakob, õigeusu variandis Jakov. Räpinas talletatud XVII saj kirjapiltidest võib välja lugeda häälduste *jaks ja *jeks variantsust. Võrdluseks võib võtta vene nimed Jakša (Я́кua), Jakuš (Я́кyu) < Jakov ning Petserimaa Jõksi küla (vn Jekšino (Екиино)) varasema nimevariandi Якушева (1790) (EKNR: Jõksi²). Perekonnanimi Jõks on peale Räpina pandud veel kahes kohas, kuid mujal võib see olla teistsugust algupära.

Kiisla. Räpina ja Võnnu kihelkonnas tuntud lisanimi on hakanud levima Mehikoormast, kus 1625 pandi kirja Kißla Jann, 1627 Kyssly Jann ja 1638 Kiszlj Jan (EAA.567.3.190:8, L 9; Rev 1627: 68; Rev 1638: 260). Talupoja lisanimi pärineb kas otseselt vene keele omadussõnast ки́сльй 'hapu' või (kaera)kiisli võrupärasest nimetusest kiisla, mis on samuti vene laensõna (<кисе́ль) (Must 2000: 97-98). Paralleele võib tõmmata ka Tveri ja Pihkva murde sõnaga kisseljai (киселяй) 'loid, halb inimene', 'nutune laps' (Dal' 1955: кисель). Vene keeles on sõnapesa aluseks väga suure esinemissagedusega perekonnanimele Kisseljov (Unbegaun 1995: 154, 313, 347). EPNRi Kiisler ei ole aga algupäraselt Räpina nimi: Helme kihelkonnas panduna on sellel ka teistsugune algupära. Siiski, Kiisleri nimekujule on osaliselt üle mindud Mehikoorma suguvõsaski, kus algkuju oli Kiislar.

Kontka. 1731 olid Toostes peremehed Konka Michl Jahn ja Konka Micko Peep (EAA.567.3.190:120, L 119p). Sama lisanime kandja Toostes pandi kirja 1625 Kondteken Jahn, 1627 Kondeka Jahn, 1630 Kondke Jahn, 1638 Konka Jan (samas: 13, L 13; Rev 1627: 71; Roslavlev 1975: 24, Rev 1638: 266). Vanim maining on Kontko Mert (Rev 1601: 18). Kõige usutavamalt on Kontka mugandus vene õigeusu nimest Копоп (Конон), samast eesnimest lähtub Ida-Soome Kontkanen (Sukunimet 1992: 216). 
Näib, et lisanime pikemale variandile vastab ka venelik hüüdvorm Kondeika (Конде́ŭка). Selle taga võib olla harva esinev r-häälikuta õigeusu nimi Kandid (Кандид), kuid mugandus on kokku käinud ka tavalise eesnimega Kondrati (Кондратий) (Petrovskij 2005: Кандид, Кондратий, Конон; Superanskaja 2010: 149). Võimalik, et suhteliselt vana Räpina lisanimi tuleneb hoopis läänekristlikust germaani nimest Konrad, mille segunemine nimega Kondrati ( $<$ kreeka Kodratos) on olnud piirialadel tavaline. Kontkar on EPNRis Räpina ainunimi.

Krõssi. Lisanimi kirjapildiga Kressi (XX saj hääldus [krõossi]) tuli kirjalikku kasutusse Lokuta külas XIX saj alguses. Õieti esineb see esimest korda just Helleri personaalraamatus Raudsepä talude elanike kõrvalnimena (PR: 22, L 104). Aleksandra Superanskaja (2010: 154) seob hüüdvormi Krõss (Kpblcb) jt lähedased variandid õigeusu ristinimega Hrisanf (Хриса́нф <Chrysantus). EPNRis on perekonnanimi Kress, mida peale Räpina on ka mujal pandud, kuid seal on see teist algupära.

Kriguli. Krigul oli Räpinas eesnimi-isanimi XVII-XVIII sajandil. 1731 oli Kurõküläs Tilla Krigula Jack ja Nahal Lude Krigola Willum (EAA.567.3.190:71, 73, L 68p, 70p). $l$-i sisaldavat vana lõunaeesti eesnime Krigul võib kõrvutada vene ja läänepoolse idaslaavi hüüdvormidega Gregolja (Грего́ля), Grigalka (Грига́лка) ja Gribal' (Гриба́ль) (Superanskaja 2010: 91-92). Algnimi on kanoonilise eesnime Gregorius õigeusu kuju Grigori (Григорий). EPNRis on Krigul Räpina ainunimi.

Mäleto. Võukülale ja Leevakule tüüpilist lisanime leidus kõige varem Võukülas: 1601 Melthe Pawell, 1627 Melleto Mick, keda on nimetatud venelaseks, 1638 Melotta Mick, 1731 Mellete Marti Peter ja Immakese Melete Jaack (Rev 1601: 16; Rev 1627: 70; Rev 1638: 272; EAA.567.3.190:89, L 88p). Lisanime päritolu kohta on kaks hüpoteesi. Lihtsam seletus on pärinemine vene õigeusu eesnimest Meleti (Меле́тий) või Mileti (Миле́тиŭ), mõlemale vastab hüüdvorm Melet( $a$ ) (Меле́m(a)), ehkki Меле́xa on tavalisem (Petrovskij 2005: Меле́тий, Миле́ти; Superanskaja 2010: 199). Alternatiivse seletuse kohaselt võiks Mäleto lisanime sisaldada Võnnu Mäletjärve küla vähemalt keskaegne nimi (1586 Maliterwe, 1627 Melk Jerwe kuella) - kohanimi, mida Jaak Simm on võrrelnud isikunimedega Melity, Melitty, Melet ja Melete (EKNR: Mäletjärve). Vormiliselt sobib Mäleto läänemeresoome omanimede hulka juhul, kui siin esineb kesksõna liide *-ttu ja esikomponent Mäle-. Võimalik, et Mäleto lisanime lühendamine perekonnanimede 
loomisel toetus mälestusele isikunimest Mäll. Wiedemanni sõnaraamatus mainitud mehenime Mäll omastavakuju on kirjapildi mõjul Mällo, aga nt Sangaste Lauküla XVI sajandist peale jälgitav talunimi on suulises kasutuses Mälu-Oti (vrd 1588 Melo Czym, PA I: 239). Kuigi vana mehenime Mäll peetakse enamasti keskaegseks Melchiori muganduseks, võiks $t$ tu-tuletise *Mälettu olemasolu näidata, et ka läänemeresoome isikunimede hulgas esines *mäle-osist. Kahjuks on seda vanade kirjalike allikate põhjal väga raske eristada palju tavalisemast meel-osisest. Kas *mälu või *mälo isikunimedes on tuletis *mäle- põhjal ning kuidas seostuvad meel ja mäletama-verb, see vajab põhjalikumat lahtikirjutamist uute avastuste valguses, mida on tehtud läänemeresoome häälikuloo uurimisel. EPNRis on Räpina ainunimed Mälberg ja Mälton (mäleto > mälto $+-n)$.

Parma. Lisanime pärinemist saab hästi jälgida vanas Kuuksi külas, kus sellest on kujunenud ka omaette väikeküla nimi. Kirjalikud mainingud ei varieeru: 1670 Parma Habsali Mert, 1731 Parma Mick (Roslavlev 1975: 28; EAA.567.3.190:52, L 50p). a-lõpulisena põhineb see lisanimi tõenäoliselt vene eesnime Parmjon (Пармён) laenatud hüüdvormil Parma (Парма) (Petrovskij 2005: Пармён). Kuigi räpina keeles on esindatud $a$-mitmus ja .parma võiks olla ka mitmuse genitiiv sõnast parm, ei ole sõnast pärineva lisanime seletus siin usutav. Ka lisanimi ise hääldub vähemalt tänapäeval teises vältes. EPNRis on Parman Parmann, hingeloendite järgi on tegu Räpina ainunimega, kuid tegelikult on see siiski ka Harjumaal tekkinud perekonnanimi.

Rikandi. 1731 oli see lisanimi Nulga külas kirjakujul Rickande, kõige varasemad samas külas olid 1601 Rikant Peter ja 1627 Rickanndt Thomas (EAA.567.3.190:97, L 96p; Rev 1601: 19; Rev 1627: 70). Kambja Veskimõisa Poka küla kunagist talunime Rekandi ja selle alusel saadud perekonnanime Rekand võiks pidada sama nime variandiks. Germaani nimel Richard ( $<*$ Rīkaharduz) põhinev Rikand oli Eestis tavaline mehenimi XVI saj, nt Halliste kihelkonnas Naistevalla külas elasid 1587 Alawe Rikand ja Weikene Rikand (PA IV: 231). Eduard Roos (1961: 350) on isikunime Rikand pidanud juba muinasaja lõpusajanditel germaanlastelt laenatud nimeks. Juhul kui see tõesti on nii, pidi kasutajate teadvuses läbi keskaja säilima Rikandi tunnetamine Richardi ristiusustamiseelse variandina, sest üldiselt kadusid muinasaegsed läänemeresoome isikunimed XV saj II poolel eestlaste hulgas käibelt. Hingeloendite järgi on perekonnanimi 
Rikand $\sim$ Rikkand Räpina ainunimi, kuid personaalraamatute järgi ehk kiriklikus liinis pandi seda nime ka Põlva ja Puhja kihelkonnas.

Rumaski. See lisanimi kujunes Räpinas XVIII saj. Väike-Veerksu Rumaskite esiisa oli 1731. aasta kirjas kui Lapi Romusch, pops Kahkva külas, kes oli tulnud 25 aasta eest Venemaalt ja võtnud kohaliku naise (EAA.567.3.190:82, L 81p-82). Lisanimi põhineb patronüümil, mis omakorda on olnud ristinime Roman (Рома́н) venekeelne deminutiiv Romaška (Рома́шка) (Superanskaja 2010: 271). XIX-XX saj setode nimevaras oli see hüüdvorm $a$-line: Ramask (Aabrams 2013: 258 ja samas teoses Hurda materjalide hulgas 1k 116). Rumask on Räpina ainunimi.

Rämmäni. Lisanimest-perekonnanimest kasutati XX saj lõpus vaid sellist omastavakuju, kuid XVIII-XIX sajandi vahetuse hingeloendites leidub nii Rämmani $\sim$ Remmani kui ka Rämma $\sim$ Remma omastavakuju. Ka Rämmän (nii nagu Rumask) oli XVIII saj ja varemgi eesnimi. Kuuksi külas sama perekonnanime saanute vanaisa oli Nietzko Remmen $\sim$ Remman (u 1707-1796). Leevakul leidub 1688 Zerna Remman, 1731 Zerna Remman Peter, Meerapalus leidub 1731 Kayo Remma Mick (SRA 1688: 264, L 261p; EAA.567.3.190:91, 117, L 90p, 116p). Eesnime lähtenimi pole selge. Sama ajajärgu nimedest võiks vene keele $a$-line Roman *[ramán] muidugi kõne alla tulla, vrd 1638 Väike-Veerksus Ramana Ein Rusze, 1731 Aravul Kücka Roman Michail (Rev 1638: 276; EAA.567.3.190:111, L 110p), ka XX saj seto traditsioonis Ramask, Rammań < Roman (Aabrams 2013: 258). Räpinas on ka mõned teised alguses tagavokaalsed nimed muutunud eesvokaalseteks, nt Tsüpsä (vanem kuju Tsupsa). Kui aga võrrelda seda Wiedemanni sõnaraamatus esineva Tartu keeleala mehenimega Rämmäl : Rämlä, siis sobib ehk paremini oletus vanemast germaani nime mugandusest, mille esisilbis oli juba keskalamsaksa keeles $e$, vrd eesnimel põhinevaid saksa perekonnanimesid Remke, Remme, Remmel(e), germaani nimede Rembert, Reinbrecht, Rembold( $t)$, Reinhold jt vanu hüüdvorme (DLF: 493). Pigem eesnimest kui puunimetusest remmel(gas) kujunenud lisanimi esineb juba XVI saj dokumentides, nt 1584 Remel Thomas Viljandimaal (PA IV: 165). Nimekuju Rämmän võib olla kujunenud vanema eesnime ühendamisel ida poolt tundma õpitud eesnimega Roman. EPNRi pääsevad sageduse alusel Räpina ainunimed Rämman, Rämmar ja Rämson.

Siila. Teated lisanime kasutusest Pääsna külas pärinevad 1670. aastast - Siela Peep. Varem oli see lisanimi olemas Väike-Veerksu külas: 1630 Syla Mert, 1625, 1627, 1638 Silla Merdt (Mart) (Roslavlev 1975: 
26; EAA.567.3.190:12, L 12p; Rev 1627: 73, Rev 1638: 276). Lisanimi põhineb kõige tõenäolisemalt vene õigeusu eesnimel Cи́ла [siila], mis on olnud kasutusel iseseisva kalendrinimena ning rohkem tuntud eesnimede Selivan ja Silvan mugandusena. Kreekakatoliku nimekalendris olevate nimede peamine alus on kreeka Silvanos (lad Silvanus) (Petrovskij 2005: Селива́н, Си́ла, Сила́н, Сильва́н; Superanskaja 2010: Си́ла). XVIII saj väga levinud Siila lisanimi võib olla Räpinas ka korduvalt tekkinud, vrd nt Venemaalt tulnud talupoja nimi Pilli Silat (1731 Veriora külas), millele vastab ilmselt ristinimi Silanti (Сила́нтий), edasiarendus kalendrinimest Silan. Siila alusnimena (või ortodoksi nimede mõjul Siilaks teisenenud vanema nimena) võib olla ka keskaegne läänekristlik nimi ${ }^{6}$. EPNRis on Räpina ainunimed Siilak, Siilbaum ja Siilivask ning Räpina-Kullamaa nimi Siilbek.

Toode $\sim$ Toodõ. Lisanimi oli XVIII saj elav eesnimi: 1738 Mehikoormas Usti Tode Ustje Todo, Jõeperal Nagla Agalick Tode, Toostes Hori Tode Peter, Kahkvas 1795 Parri Tode t. Katri (EAA.567.3.191:40, 64, 65,81 , L 40p, 83p, 84p, 55p). Varasema perioodi lisanimena seda Räpinas ei esine. Kui nt Toots on 1688. aasta maarevisjonis korduv eesnimi, siis Toode esineb vaid korra: Silla Tode Nulga külas (SRA 1688: 218, 268, L 215p, 265p). Räpina venelastel XVIII saj hästi tavalist eesnime kirjapildiga Fedor $\sim$ Födor $\sim$ Tedor ei saa kuidagi Toodega siduda, kuid vasteks võiks sobida Theodori läänekristliku kuju vene mugandus Todja (Тодя), vrd ka Theodotuse (vn Федот) hellitusvorm Dotja (Дотя) (Petrovskij 2005: Теодор, Федот). Kohaliku hüüdvormi tekkimise aeg näib olevat XVII sajand, kuid see vorm oli levinud ka mujal Võrumaal. Kõige usutavamalt on tegu palju vanema eesnime Toots põhjal tekkinud variandiga. Tootsi omakorda on Marja Kallasmaa EPNRi käsikirjas õnnestunult sidunud Theodotuse idakristliku kujuga Фedom (Kallasmaa jt 2017: 935). Teine võimalus seletada eesnimede Toode ja Toodo päritolu on keskajast säilinud germaanipäraste nimede hüpokorism Dodo, saksa perekonnanimena ka Dode, mida on ajalooliselt kasutatud nt Ludolfi ja Dietrichi hellitusvormina (DLF: 173). EPNRis on Räpina ainunimi Tooding ja mitmes muus Lõuna-Eesti kihelkonnas pandud Toode.

Viia. Räpina lõunaosas seeria perekonnanimesid andnud lisanimi hakkas levima pigem kihelkonna keskosast. 1638 on Võukülas elanud Wiha

${ }^{6}$ Fred Puss on juhtinud tähelepanu, et Edgar Rajandi on seostanud nimed Sille, Silli jt St Gillesiga (Rajandi, Dequeker 1981: 362). 
Peter, keda on nimetatud venelaseks. 1638 on ka Ihamaru külas (Kanepi khk) elanud Wiha Jurgen ja Wiha Pep (Rev 1638: 272, 290). Mõlemas kohas on Viia nimi säilinud talunimena. Võuküla Viia varaseimad mainingud on 1625 Woy Jack Wya Jack Wia Jack ja Wya Andreas,1627 Weyba Jack, 1630 Wia Petter (EAA.567.3.190:10, 13, 22, L 10, 13, 22; Rev 1627: 70; Roslavlev 1975: 24). Vanim maining on Wiakes Hans Pahtpää külas (Rev 1601: 15) - selles võib ära tunda *Viiakeste nimekuju. Kõige usutavamalt võiks Viia-lisanimi põhineda muinasajast pärandunud isikunimel, mille tüvi kujul *viha-(Stoebke 1964: 105) näib olevat õige mitme vana kohanime aluseks üle Eesti, muu hulgas Urvaste kadunud külanimi Wyasth $\sim$ Wiast $\sim$ Wihhaste (vrd EKNR: Hargi, Vihasoo, Vihavu, Vihula, Viimsi). Täienduseks tuleb mainida, et kui teise silbi $h$ sellest nimest kadus, siis XVII ja XVIII saj kirjapiltides esinev $h$ ei ole mitte arhailine nimekuju, vaid $i$ pikkuse rõhutamiseks lisatud $h$. EPNRis on Räpina ainunimed Vija Viia, Vijand, Vijar ja Vijard.

\section{Kokkuvõte}

Perekonnanimede panemisele Räpinas eelnes pastor Helleri põhjalik huvi talupoegade lisanimede vastu. 1816. aastal alustatud personaalraamatusse on teadlikult kogutud perede ametlikke ning suulisi lisa- ja hüüdnimesid. Personaalraamat ei dokumenteeri otseselt kõiki lisanimedest tehtud tuletisi, mis perekonnanimedeks pandi, ning neid on sinna kantud tagantjärele.

Kui läheneda Räpina nimetuletusele tuletamata nimede ja lühemate nimelõppude poolelt, siis selgub, et nimelõppudes kasutas Heller nii saksa, Iõunaeesti kui ka vene keele vahendeid, sõnalistes formantides aga saksa keelt. Osa nimelõppudest oli juba enne olemas pikemates kohalikes lisanimedes. Mõni korduv nimelõpp polnud teadlikult valitud, vaid need hakkasid korduma lisanimede ja lühema nimelõpu liitumisel ning võeti siis kasutusele kui iseseisvad, keelemängulised nimelõpud. Nii kujunesid lisanimede lõppudest ja kohaliku keele $n d$-tuletussufiksist uued lõpud -kind ja -land. Kohaliku tuletussufiksi -ng kasutamine võis anda tõuke ka saksa keele jaoks arhailise -ing kasutuselevõtuks. Korduma hakanud lisanimelõppude ja lõpu -ing mõjul juurdusid omakorda -sing ja -ding. Lisanimele $r w$-d liites tekkis saksapärasena tajutav -dorw. Mann-formandiga nimesid edasi tuletades saadi iseloomulik nimelõpp -mannson. 
Nimelõppe liites lühendas Heller lisanimesid oskuslikult. Ilmselt saatis kogu tegevust ka taotlus saada rütmiliselt kõlavaid nimesid, mis oleksid pikkuselt ja kõlalt sarnased eksootiliselt kõlavate lisanimedega, mida ta Räpinas oli tundma õppinud. Paljud pikemad Räpina perekonnanimed on liitnimed, mis sisaldavad kaht lisanime, sagedamini küll lühendatud segmente kahest lisanimest. Juba tuletatud lõpuga perekonnanimedele veel üht lisanime lühendust ette lisades saadi ka kolme komponenti sisaldavaid nimesid. Sageli vastab kolmele komponendile nimes siiski vaid kolm silpi. Ükski Räpinas pandud perekonnanimi pole pikem kui neljasilbiline.

Valik leidudest ja dilemmadest räpinapäraste lisanimede etümologiseerimisel (17 lisanime umbes 82 hulgast) ei ole mingis mõttes esinduslik, kuid valikusse on püütud võtta just selliseid lisanimesid, mis on läbipaistmatud ja saadud isikunimedest, kunagistest individuaalnimedest/ eesnimedest. Ainus erand on Kiisla, mis näib olevat apellatiivse taustaga algupärane lisanimi. Räpina lisanimevara põhineb valdavalt isikunimedel. Ametiga seotud ja loodusnimedel põhinevaid lisanimesid leidus XIX saj alguses Räpinas palju harvem kui nt Rõuges või Urvastes.

Kui uurida lisanimede allikaid ja levikupilti, tekib ettekujutus, kas mõni lisanimi põlvneb sellisest ajast, milleni ei ulatu kirjalike allikate haare (1582. aastale eelnevast ajast), ilmub pärast XVII saj alguse suurt rahvastikukatastroofi ja mitmest suunast lähtunud rännet või tuleb dokumenteeritud eesnimena kasutusele alles XVIII saj. Näiteks toodud lisanimede hulgas on kaks sellist, mida julgeksin pidada muinasajast pärinevate isikunimede järeltulijaiks: Viia ilma kõhkluseta *viha-nimeelemendi rühma kuuluvana ja Mäleto teatava kõhklusega, sest see võib pärineda ka XVI saj piirialal levinud vene ristinime hüüdvormist Meleta. Vana ja varakult laia levikuga Häide põhineb pigem keskaegsel laennimel, sama võiks väita vana ja kaua ühes külas püsinud Rikandi kohta. Samas pole välistatud nende isikunimede tuntus Eestis juba enne XIII saj.

Tutvustamiseks valitud lisanimedest suurem osa on venepärase taustaga: Haavakari, Härso, Kiisla, Kontka, Krõssi, Kriguli, Parma, Rumaski ja Siila. Siin esineb eripalgelisi juhtumeid, nagu väga vana lisanimi Kontka, lisanimena alles XIX saj ilmuv Krõssi, kohapeal peamiselt XVIII saj eesnimedena laiemalt levinud Haavakar, Krigul ja Rumask. Lisanimi Jõksi võiks liigituda Võrumaa kohalikuks arenguks venepärase Jakša taustal. Eesnimi Rämmän näib põlvnevat vanemast lõunaeesti nimest, kuid seda saab siiski ühendada ka Romaniga. Samuti eesnimena käibinud Heering 
võiks olla XVII saj tundma õpitud nime Erik mugandumise näide, seevastu nimes Toode peegeldub traditsioonilise Tootsi ja vene nimemuganduste jätkuv vastastikmõju samal ajajärgul.

Kohaliku vene vähemuse ja sisserändajatega kontaktis olnud Räpina on hea näide nimesüsteemi kohta, mis põhineb naaberkeelest sajandite jooksul tasapisi lisanduvatel isikunimedel, mida on oma tarbeks ümber töötatud. Talupoegade lisanimed on siin olnud keeleliselt pigem läbipaistmatud, kuid neil on olnud keskne koht nimesüsteemis. Tänu unikaalsele perekonnanimede tuletamise eksperimendile elavad Räpina vanad lisanimed tänapäevani rahvasuus ja see teeb nendest eriti tänuväärse uurimisobjekti.

\section{Kirjandus}

Aabrams, Vahur 2013. Vinne õigõusu ristinimeq ja näide seto vastõq. - Raasakõisi Setomaalt. Setomaa Hurda Jakobi silmi läbi aastagil 1903 ja 1886. (= Seto Kirävara 6.) [Värska]: Seto Instituut, Eesti Kirjandusmuuseum, 231-256.

Dal' 1955 = В. И. (Владимир Иванович) Даль. Толковый словарь живого великорусского языка. T. I-IV. Москва.

DLF $=$ Duden Lexikon der Familiennamen von Rosa und Volker Kohlheim. 2008. Mannheim jt: Dudenverlag.

Ehrlich, Miralda 2006 [1931]. Ajaloolist traditsiooni Räpina kihelkonnast. Räpina ja Kahkva valdadest. http://www.folklore.ee/pubte/ajaloolist/ rapina/ (vaadatud 15.01.2019).

EKNR = Marja Kallasmaa, Evar Saar, Peeter Päll, Marje Joalaid, Arvis Kiristaja, Enn Ernits, Mariko Faster, Fred Puss, Tiina Laansalu, Marit Alas, Valdek Pall, Marianne Blomqvist, Marge Kuslap, Anželika Šteingolde, Karl Pajusalu, Urmas Sutrop 2016. Eesti kohanimeraamat. Toim. Peeter Päll, Marja Kallasmaa. Eesti Keele Instituut, Võru Instituut, Eesti Kirjandusmuuseum. Tallinn: Eesti Keele Sihtasutus.

EPNR = Eesti perekonnanimeraamat. Käsikiri. Eesti Keele Instituut, Võru Instituut, Eesti Kirjandusmuuseum.

Kallasmaa jt 2017 = Marja Kallasmaa, Udo Uibo, Peeter Päll. Eesti perekonnanimeraamatust. - Keel ja Kirjandus 12, 926-938.

Kask, Arnold, Heli Laanekask 1987. J. F. Helleri eesti-saksa sõnaraamat. - Keel ja Kirjandus 8, 468-479.

Must, Aadu 1995. Nimi ajalooallikana. - Allikad ja uurimused $=$ Sources and Research. (= Pro Ethnologia 3.) Tartu: Eesti Rahva Muuseum, 156-170.

Must, Mari 2000. Vene laensõnad eesti murretes. [Tallinn]: Eesti Keele Sihtasutus. 
PA I = Polnische Akten I, 1582-1591. 1970. - Hefte zur Landeskunde Estlands. Heft 5. Hrsg. Oleg Roslavlev. München.

PA II = Polnische Akten II, 1586-1616. 1973. - Hefte zur Landeskunde Estlands. Heft 7. Hrsg. Oleg Roslavlev. München.

PA IV = Polnische Akten IV, 1583-1590. 1973. - Hefte zur Landeskunde Estlands. Heft 6. Hrsg. Oleg Roslavlev. München.

Petrovskij, Nikandr $2005=$ Н. А. Петровский. Словарь русских личных имен: более 3000 единиц. Москва: Русские словари: Астрель: АСТ.

PTK I $=$ Valdek Pall 1969. Põhja-Tartumaa kohanimed. I. Tallinn: Valgus.

Rajandi, Edgar, Michel Dequeker 1981. Anthroponymes et toponymes d'origine latine et française en Estonie. - Congressus Quartus Internationalis Fenno-Ugristarum. Budapestini habitus 9.-15. Septembris 1975. Pars III. Acta sectionis linguisticae. Budapest, 359-363.

Rev $1601=$ Die Revision Livlands 1601. Estnisches Siedlungsgebiet. 1967. Hrsg. Oleg Roslavlev. (= Hefte zur Landeskunde Estlands 3.) WolfratshausenWaldram.

Rev 1627 = Das Dorpater Land 1624/27. 1965. Hrsg. Oleg Roslavlev. (= Hefte zur Landeskunde Estlands 1.) Wolfratshausen-Waldram.

Rev 1638 = Liivimaa 1638. a. maarevisjon. Eesti asustusala. I. Kaguosa. 1041. (= ENSV Riigi Keskarhiivi Tartu osakonna toimetused 1 (7).) Tartu: Teaduslik Kirjandus.

Ritsing, Richard 1984. Räpina perekonnanimedest. - Räpina radadel. Tallinn: Eesti NSV Teaduste Akadeemia, 159-161.

Roos, Eduard 1961. Eesti muistseist isikunimedest. - Keel ja Kirjandus 6, 341-352.

Roslavlev, Oleg 1975. Siedlungsgeschichte des Estenlandes. Zur Siedlungsgeschichte des Kirchspiels Rappin (Kreis Werro). München.

Saar, Evar 1999. Inemisenimmi ja kotussõnimmi läbikasumisõst Räpinä kihlkunnan. - Õdagumeresoomõ veeremaaq. Läänemeresoome perifeeriad. Toim. Karl Pajusalu, Tõnu Tender. (= Võro Instituudi toimõtisõq 6.) Võro: Võro Instituut, 80-92.

Stoebke, Detlef-Eckhard 1964. Die alten ostseefinnischen Personennamen im Rahmen eines urfinnischen Namensystems. (= Nord- und osteuropäische Geschichtsstudien IV.) Hamburg: Leibniz-Verlag.

Sukunimet $=$ Pirjo Mikkonen, Sirkka Paikkala 1992. Sukunimet. Toinen painos. Helsingissä kustannusosakeyhtiö Otava.

Superanskaja, Aleksandra $2010=$ Александра Васильевна Суперанская. Словарь народных форм русских имен. - Москва: Книжный дом "ЛИБРОКОМ".

Unbegaun, Boris Ottokar 1995 = Унбегаун, Б.-О. Русские фамилии. Перевод с английского. Москва: Прогресс-Универс. 
VEV = Võro-eesti-võro sõnaraamat. https://synaq.org/ (vaadatud 15.01.2019).

Wiedemann $=$ Ferdinand Johann Wiedemann 1973 [1893]. Eesti-saksa sõnaraamat. Neljas, muutmata trükk teisest, Jakob Hurda redigeeritud väljaandest. Tallinn: Valgus.

\section{Arhiiviallikad}

\section{Rahvusarhiiv}

PR = EAA.1269.1.796 - Räpina koguduse personaalraamat 1816-1831, 1851. EAA.1865.2.71/1-7 - 1826. a hingeloenduse vaherevisjoni Kahkva, Meeksi, Palo, Räpina, Ruusa, Veriora mõisa ja Räpina kirikumõisa revisjonilehed. EAA.1865.2.70/13-19 - 1816. a hingeloenduse samade mõisate revisjonilehed ja ümberkirjutuslehed.

EAA.1865.2.70/5, 7-12 - 1811. a hingeloenduse samade mõisate revisjonilehed. EAA.1865.2.70/1-4 - 1795. a hingeloenduse Kahkva, Meeksi, Palo ja Räpina mõisa revisjonilehed.

EAA.1865.2.132/13 - 1816. a hingeloenduse Urvaste mõisa revisjonilehed ja ümberkirjutuslehed.

EAA.567.3.191 - Räpina mõisa (kogu kihelkond) 1738. a spetsifikatsioon ja vakuraamat.

EAA.567.3.190 - Räpina mõisa (kogu kihelkond) 1625. a maksualuste talupoegade nimekirju (säiliku alguses), 1731. a spetsifikatsioon ja vakuraamat.

\section{Rootsi riigiarhiiv}

SRA 1688 = SRA Östersjöprovinsernas jordrevisionshandlingar 55410/36. Livland Revisionsjordebok 1690 (1687-1692). Dorpats krets. Sockarna: Wendau, Rappin, Pölwe, Rauge, Neuhausen. Rootsi Riigiarhiivi säiliku digikuju Rahvusarhiivi Saagas, milles sisaldub muu hulgas Räpina mõisa (kogu kihelkond) vakuraamat ja maarevisjon 1688. 


\title{
Räpina family names and bynames ${ }^{7}$
}

\author{
EVAR SAAR
}

The article examines the creation of family names on the example of Räpina parish. Family names were derived from authentic bynames by the pastor J. F. Heller, who had previously collected vocabulary items for a dictionary and shown interest in the bynames of peasants. In his register of parishioners, begun in 1816, he collected different families' formal and spoken bynames and nicknames.

Heller used German, South Estonian and Russian name suffixes, which he combined with German vocabulary elements. Many name suffixes were already in existence in longer local bynames. Some repeating name suffixes had not been consciously chosen, they emerged by chance and later began to be used as independent name suffixes. In this way, the new suffixes -kind ja -land developed from the ends of bynames and the -nd derivational suffix found in the local language, e.g. the byname Naruski + the suffix $-n d=$ the family name Naruskind, by analogy to which the family name Häide $+-k i n d=H a ̈ i d k i n d$ was created. The use of the local derivational suffix -ng could have motivated the use of the suffix -ing (archaic in German), e.g. Viki $+-n g=$ Vikking $>$ Parma +- ing $=$ Parming. The derivation developed beyond that as well: Härso + -ing $=$ Härsing $>$ suffix -sing, e.g. Jaago + -sing = Jagosing.

By combining name suffixes, Heller capably shortened many bynames. He was also clearly motivated by the desire to obtain rhythmically appropriate names, which would be similar in length and sound to the exotic-sounding bynames that he had become familiar with in Räpina. Many of the longer Räpina family names are compound names containing two bynames.

The second half of the article deals with the etymology of the bynames chosen as sources for Räpina family names. The bynames examined herein are mostly opaque and derived from personal (given) names.

Of the bynames whose etymology is discussed in the article, two (Viia and Mäleto), can be considered to be based on ancient personal names. By contrast, the bynames Häide and Rikandi are more likely based on medieval loan names ( $<$ Germanic Heidrich and Richard). However, it is not impossible that these personal names were known in Estonia even before the 13th century.

7 Byname - a name used in addition to the given name, which may be inherited but does not necessarily remain the same throughout a person's life. 
Most of the bynames discussed in the article are of Russian origin: Haavakari, Härso, Kiisla, Kontka, Krõssi, Kriguli, Parma, Rumaski and Siila. Having been in contact with the local Russian minority and with immigrants, Räpina represents a good example of a naming system that has gradually adapted personal names arriving from a neighbor language over the centuries. Peasants' bynames in Räpina have tended to be linguistically opaque, but they have played a central role in the naming system. Thanks to the unique system of family name derivation, the old Räpina bynames live on to the present day.

Keywords: family names, bynames, name derivation, etymology

\section{Evar Saar}

Võru Instituut

Tartu 48

65609 Võru

saareevar@gmail.com 